\title{
Extending LIP to Provide an Adaptive Mobile Learning
}

\author{
doi:10.3991/ijim.v3i1.763 \\ Mona Laroussi ${ }^{1,2}$, Alain Derycke ${ }^{2}$ \\ ${ }^{1}$ Riadi Laboratory /ENSI , Tunis, Tunisia \\ ${ }^{2}$ LIFL Laboratory - Lille 1 University Lille France
}

\begin{abstract}
In this paper, we discuss the issue of adaptativity in mobile learning. To adapt a system, we need a learner model. We discuss the limits of learner model in the environment of mobility. We present LIP (Learner Information Package) and we propose an extension of LIP (C-LIP) in order to take into consideration new dimensions induced by mobility. To test this extension, we conceive and develop a prototype of an editor aiming at assisting the teacher in the implementation and in the update of C-Lip.
\end{abstract}

Index Terms_adaptativity, context, mobile learning, learner context, LIP

\section{INTRODUCTION}

We are currently working on solutions to provide adaptativity in an environment of mobile learning. we particularly investigate how to integrate the advantages of mobile learning with strategies and techniques successfully employed in web-based educational systems, especially methods and techniques developed for adaptive educational hypermedia systems. Research in adaptive educational hypermedia has ascertained several techniques for navigational level and content level adaptation [11].

In adaptive educational hypermedia, the focus is on the learner. In fact, adaptativity implies the integration of a learner model in the system and uses this model to adapt navigation, content and interaction.

In this regard, the past eight years have seen a rapid growth in research, development and deployment of mobile technologies to support learning. Although research in this area began with the seminal work of Kay and colleagues at Xerox PARC [10] it is only recently that both technology and educational needs have converged. The new technology includes multimedia-equipped mobile phones, personal digital assistants (PDAs) and pen tablet computers; the new emphasis in education is on supporting the learner, in collaboration with peers and teachers, through a lifetime of education, both within and outside the classroom [11].

However, the majority of mobile learning systems do not take into account the heterogeneous needs of learners by providing them with the same learning material and process to learners without taking into account their various contexts. A solution to this problem can be best achieved through the use of learner models used in the traditional learning system or in hypermedia system.

The combination of learner model standards with current and emerging mobile technologies offer better information presentation that take into account the characteristics of the learner performing the search; thus, achieving personalized adaptive learning.

This paper is concerned with extending the standard related to the learner model to support context of mobile learning. The paper is structured as follows: Section 1 deals with the terminology necessary to understand the paper. Section 2 gives an overview of the main issues and requirements related to learner models. Section 3 introduces the most important standards dealing with learner modeling with an emphasis on LIP, Limits of LIP in a mobile learning context and possible extension. Section 4 presents the extension proposed in learner model and so Extended LIP editor (C-LIP). Finally, Section 5 gives a summary of the paper and outlines perspectives for the future.

\section{BACKGROUND}

This section presents the definitions and standards associated with this work. The mobile learning is described in section A. Section B presents the context and the different elements composing it includes.

\section{A. Mobile Learning}

Mobile learning: is learning through mobile computational devices: Palms, Windows CE machines, even digital cell phone.

The vision of mobile computing is that of portable computation with rich interactivity, total connectivity, and powerful processing. This small device is always networked, allowing easy input through pens and/or speech or even a keyboard when necessary (though it may be something completely different like a chord keyboard), and the ability to see high resolution images and hear quality sound. It may be that the image is overlaid on the world through glasses that act like a Heads Up Display.

Mobile learning can be considered from two viewpoints. The first one is a technically oriented perspective regarding traditional behaviorist educational paradigms as given and tries to represent or support them with mobile technologies. A main concern from this perspective is how to create, enrich, distribute and display learning material on mobile devices; the main benefits are to personalize the way of learning (where you want, when you want, what you want, as fast as you want, how you want; etc.) [12].

The second one, learning is not only the simple use of mobile devices for pedagogical purposes; even if this mobility favors the distant learner, but it gives a broader definition of mobility. By this second definition we think about the continuous connectivity (anytime and 
anywhere), the distributed task between wired and wireless devices, intense interaction between learner and environment.

Mobile learning is becoming widely accepted. There is a need to reduce time away from the job to deliver in a more flexible and highly adaptive way

Some students live in distant or rural areas with poor transportation systems thus it is important to reduce the costs of delivering training to large numbers of people.

people need to access instructional content 24 hours a day, seven days a week, or just in time while on their jobs. In addition in mobile learning, we can collaborate and cooperate to solve a special task. We can also access to learning material in a free way - any time in any place and with any device - but this freedom impose new constraints linked to the whole environment (indoor and outdoor) thus two notions appear context and context-aware.

\section{B. Context}

Based on previous definitions [4][7][15][1][13][16] and previous work [14]. In mobile learning environment, we have defined context as a set of element that we consider appropriate to favourite interaction between the user and the application.

Given the diversity of context information, it is useful to attempt to categorize it to make it easier to apprehend in a systematic manner. To this aim, we introduce a simple classification of context information, based on categories of contextual information.

We introduce two essential categories of context information-individual context and shared context [14].

Individual context includes information relevant to the interaction between the learner and mobile learning applications.

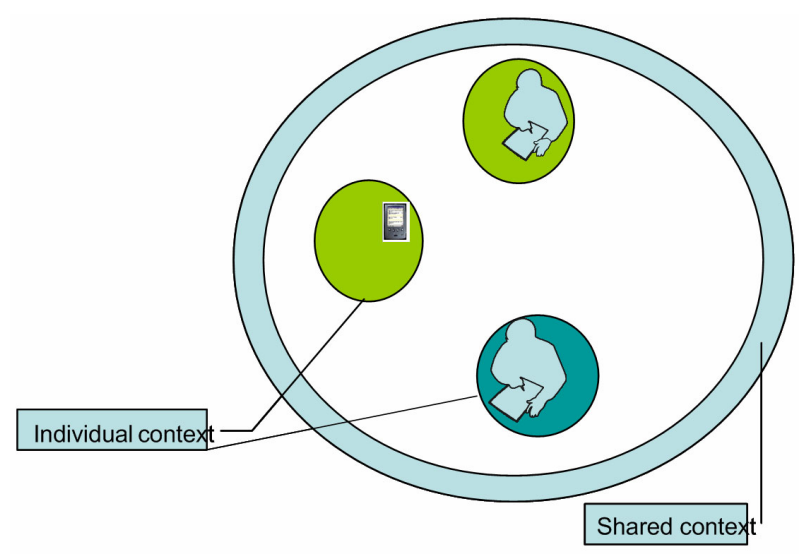

Figure 1. Shared and individual context in mobile learning

Shared context includes information relevant to collaborative group work or learners sharing common interests. (figure 1).

\section{LEARNER MODEL}

\section{A. Definition}

A learner model represents relevant learner characteristics, like preferences, knowledge, competencies, tasks, or objectives. The majority of educational adaptive hypermedia systems use an overlay model of user knowledge [2]. The key principle of the overlay model is that for each domain model concept, an individual user knowledge model stores some data that is an estimation of the user knowledge level on this concept. A weighted overlay model of user knowledge can be represented as a set of pairs "concept-value”, one pair for each domain concept. Some systems store multiple evidences about the user level of knowledge separately. Another alternative to model the user knowledge is provided by a historic model that keeps some information about user visits to individual pages. Some systems use this model as a secondary source of adaptation.

The learner's goals can be modeled as a set of concepts (competencies) that can be represented similarly to the overlay model. Additionally to these dynamic dimensions the learner model includes also a more static one - user preferences. The most relevant ones are preferred cognitive and learning styles, as well as the language.

The following standards relate to user modelling:

IEEE Public And Private Information - specifies both the syntax and semantics of a 'Learner Model,' which will characterize a learner and his or her knowledge/abilities.

IMS Learner Information Package - learner information data exchange between systems that support the Internet learning environment.

\section{B. Learner model in adaptive mobile learning}

We can define an adaptive mobile learning as a mobile system which supports both learner adaptation and device adaptation for constructing an adaptive learning content.

We can distinguish two approaches for adaptation, learner adaptation is to present learning contents based on the profiles and preferences of individual learners. Device adaptation is the process of automatically transforming the source content to an adaptive content according to the specifications of mobile devices (screen size, resolution, alimentation, etc.).

To provide adaptive content, we need information about learner and his environment. Information about learner is stored on a learner model that should be maintained.

\section{C. . Standards for Learner Model}

The two most important standards for learner modeling are IEEE LTSC Personal and Private Information Standard (PAPI) [22], and IMS Learner Information Package (LIP) [21]. Both standards deal with several related categories of information about a learner, some of them are used in this work. Characteristics of the main standards of learner models are presented next.

The IMS LIP standard contains several categories of data about a user. The identification category presents demographic and biographic data about a learner. The goal category presents learner targets, career expectation and other objectives. The QCL category is used for the identification of qualifications, certifications, and licenses from recognized authorities. The activity category contains learner-related activity in any state of completion. The interest category maintains any information describing learner hobbies and recreational activities. The relationship category maintains relationships between core data elements. The competency category serves as slot for skills, experience and knowledge acquired. The accessibility category points toward general accessibility to learner information by means of language capabilities, disabilities, eligibility, and learning preferences. The 
transcript category presents a summary of academic achievements. The affiliation category presents information about membership in professional organizations. The security key is used for setting learner passwords.

The PAPI standard distinguishes personal, relations, security, preference, performance, and portfolio learner information. The personal category contains information about names, contacts and addresses of a learner. Relations serve as a category for relationships of a specific learner to other persons (e.g. classmate).

Security aims at providing access rights. Preference indicates the types of devices and objects which the learner technological support is able to recognize. Performance contains information about measured performance of a learner through learning material. Portfolios access the previous experiences of a user.

Many tools exist enabling conversion between two standards.

There are other proposals for a standardization of the learner data, but they not enter the objective of this paper. We can note two standards AICC3 and SCORM. The standard SCORM offers a data model for managing all the learning productions. This model comprises a set of fields in order to allow a standardized exchange of data between a runable training unit and the platforms.

The learner's follow-up was one of the principal concerns of AICC. In this model, the data exchanges between the learning system and a given training module are done via files. This approach allows the division of data between several modules constituting the training.

\section{LIP (IMS)}

\section{A. Definition}

Learner Information is a collection of information about a Learner (individual or group learners) or a Producer of learning content (creators, providers or vendors). The IMS Learner Information Package (IMS LIP) specification addresses the interoperability of internet-based Learner Information server may exchange data with Learner Information systems with other systems that support the Internet learning environment. The target of the specification is to define a set of packages that can be used to import data into and extract data from an IMS compliant Learner Information server, a Learner Delivery system or with other Learner Information servers. It is the responsibility of the Learner Information server to allow the owner of the learner information to define what part of the learner information can be shared with other systems. The core structures of the IMS LIP are based upon: accessibilities; activities; affiliations; competencies; goals; identifications; interests; qualifications, certifications and licences; relationship; security keys; and transcripts.

\section{B. Concept}

The Learner Information Packaging Requirement Specification [21] introduced the base learner information system architecture. The underlying process components (circles) and data structures (thin rectangles) and the actors (stick-people) are shown in Figure 2.

The key components of the learner information system are:
- Local learner information system - local server(s) that are directly accessible by the corresponding user community;

- Remote learner information system - a reflection of the distributed nature of a learner information server, i.e. different parts of the 'learner information' could be stored on several servers;

- Other systems - others systems that may be interconnected to the learner information servers e.g. e-mail. The interfaces to these systems are beyond the scope of this specification;

- Data structures;

- Learner info - the actual learner information data itself;

- Access - the access rights to the learner information data i.e. who can see what;

- Messaging - the messaging protocol used to implement the actual profile interchanges; and

- Actors - the different roles of the users accessing a profile server. The different actors shown in Figure 2 are not an exhaustive list.

\section{Learner Data Structure}

The Learner information is separated into eleven main categories. These structures have been identified as the primary data structures that are required to support learner information. This composite approach means that only the required information needs to be packaged and stored.

- Identification: Biographic and demographic data relevant to learning;

- Goal: Learning, career and other objectives and aspirations;

- Qualifications, Certifications and Licenses (qcl): Qualifications, certifications and licenses granted by recognized authorities;

- Activity: Any learning-related activity in any state of completion. Could be self-reported. Includes formal and informal education, training, work experience, and military or civic service;

- Transcript: A record that is used to provide an institutionally-based summary of academic achievement. The structure of this record can take many forms;

- Interest: Information describing hobbies and recreational activities;

- Competency: Skills, knowledge, and abilities acquired in the cognitive, affective, and/or psychomotor domains;

- Affiliation: Membership of professional organizations, etc. Membership of groups is covered by the IMS Enterprise specification;

- Accessibility: General accessibility to the learner information as defined through language capabilities, disabilities, eligibilities and learning preferences including cognitive preferences (e.g. issues of learning style), physical preferences (e.g. a preference for large print), and technological preferences (e.g. a preference for a particular computer platform);

- Security key: The set of passwords and security keys assigned to the learner for; 


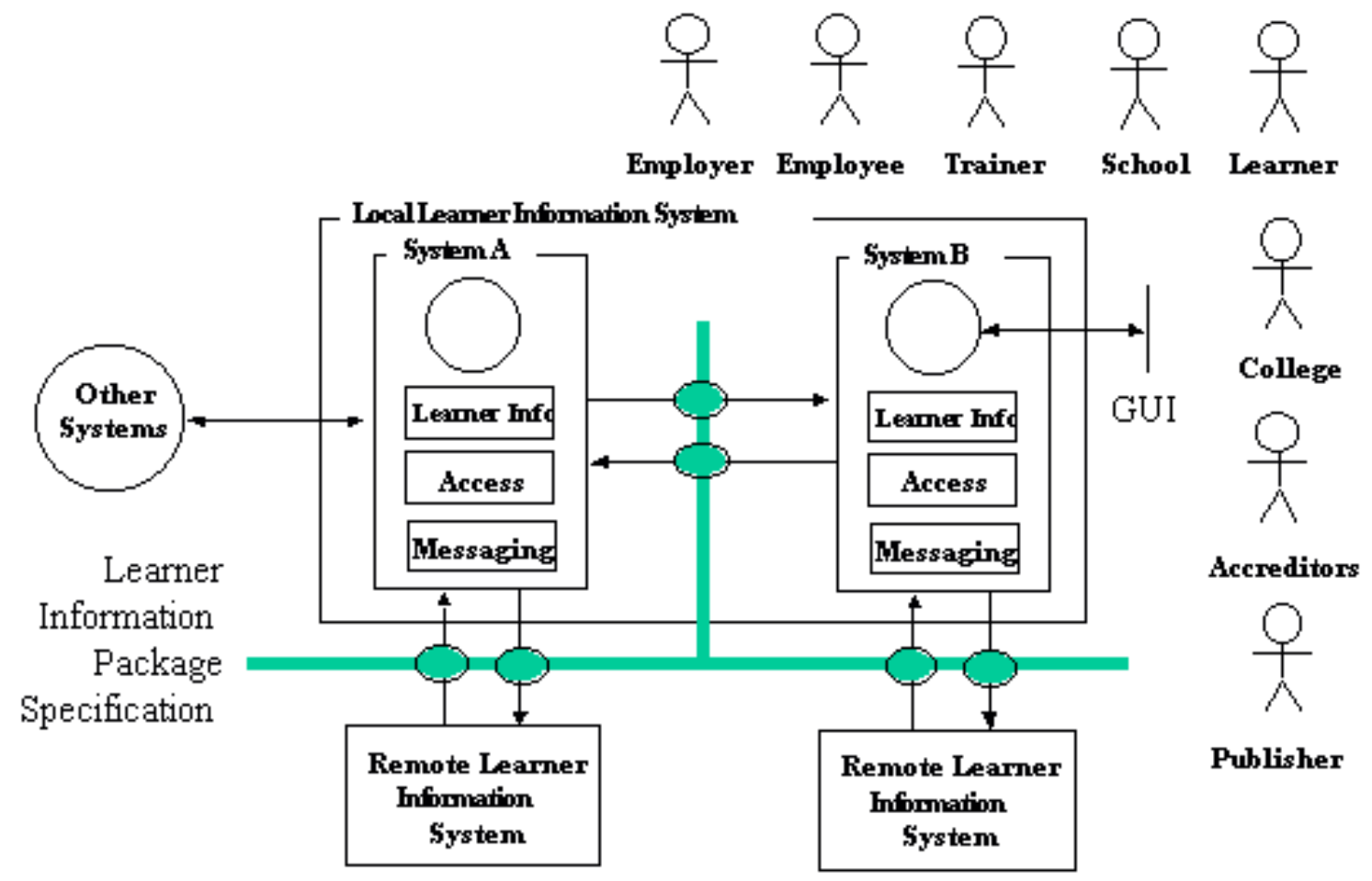

Figure 2. Learner information system component representation

- transactions with learner information systems and services; and

- Relationship: The set of relationships between the core components. The core structures do not have within them identifiers that link to the core structures. Instead all of these relationships are captured in a single core structure thereby making the inks simpler to identify and manage.

\section{LIMITS OF LIP IN MOBILE LEARNING ENVIRONMENT}

The LIP Standard was initially designed to describe the learner without considering a mobile learning environment.

However, the availability of wireless technologies and the popularity of handheld devices have opened up new accessible opportunities for education: mobile learning. Hence, the LIP core specification becomes unsuitable to satisfy the new constraints imposed by this new learning environment. Indeed, the design features such as the volatile memories or the interfaces (screen, stylet..) raise strong constraints. They impose a reflection on the fond and the form of the pedagogical subjects to present. Thereafter, we describe two different scenarios in order to explain LIP Limits.

\section{A. Scenario 1}

Alice is a master student at university in Paris. The number of hours studied in her master is very tiny.

Thus Alice decided to seek a work in a company in Marseille. She plans to follow her studies via her mobile phone when she cannot attend the courses.

Alice faces a problem when she knows that it was proved that the profile and registration preferences must be done respecting LIP specification.
The standard does not specify preferences about her device nor the context of the environment in which she will study.

This can have bad consequences on the content and the presentation of her learning activities.

\section{B. Scenario 2}

Alain is a service boss in a factory. He spends most of his time far from his work place because of his various commitments. The team reporting to him is generally faced with problems when using new machines. To resolve problems, the worker on the machine must contact him.

In order to facilitate the resolution of these problems, the factory finds the following solution: provide each worker with a PDA to contact the expert via Internet.

To contact the expert, any employee (learner) must be identified, and information taken by sensors integrated in the PDA (the ambient temperature, frequencies of noise which it releases...) must be provided to the expert who offers the precise solution according to case description, and the worker concerned.

This information provided to the expert must respect LIP specification. Very quickly the company was unable to carry out its objective because of the limits of the LIP core. The components of the standard did not allow a rich description of the work context of learner.

\section{Synthesis}

From these two scenarios, we can see that the current structure of LIP does not support the mobile learning. Indeed the current version of LIP does not allow a geographical representation of learner and does not allow adapting the contents to the mobile devices by 
taking account the various contextual elements described in section 2.B.

Our objective is to define a new LIP core component that allows adaptive mobile learning (and the definition of he various parts needed for mobile learning).

\section{From LEARNER MODEL TO CONTEXT MODEL}

Most of previous and current works on adaptive elearning focus on user model [11][6] which takes into account only internal environment of the user: personal information, interest centers, preferences... etc. but the rush of the wireless and mobile technologies has created a move from e-learning to m-learning and P-learning (pervasive learning).

An efficient mobile learning system has to be sensitive not only to the user model information but also to the whole context that characterizes the interactions between users, applications and the surrounding environment. For that, we attempted to extend the learner model into more abstract learner context model that includes the user model and gathers all contextual elements relevant to pervasive and mobile learning systems.

Many of the traditional learner model attributes remain relevant (knowledge, preferences, misconceptions, etc.), but there are also issues that do not usually apply in PC environments. For example, how may location of the user affect an interaction? How desktop and mobile PCs might be integrated to allow the user to interact with whichever device is most convenient at the time (cf Figure 3).

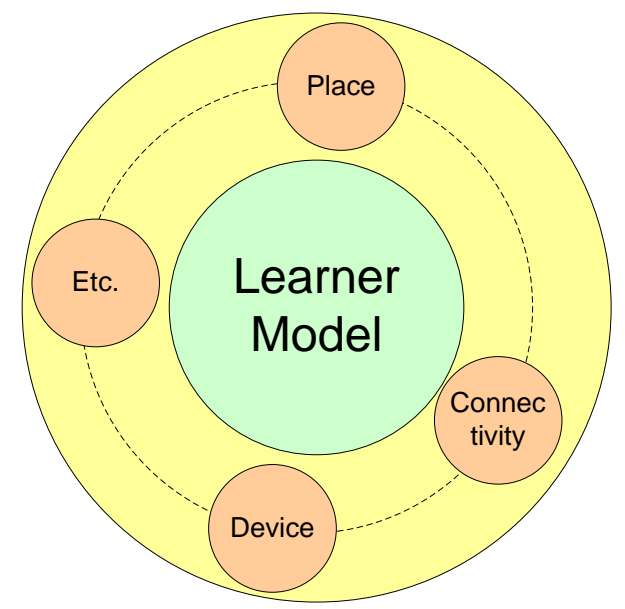

Figure 3. New dimensions for learner model induced by mobility

\section{EXTENDED LIP: C-LIP}

In a situation of mobile learning, besides the traditional elements which are in relation with pedagogy, logistics and the model of learning, new elements appear: these elements can be summarized by the context as have been presented above.

We thus thought of adding an element context to LIP. But the element context already exists. We therefore took into account this element to show the limits of these components and to modify them with regard to our contextual elements.

\section{A. The context in LIP}

The introduction of the context into the LIP was carried out by IMS which performs updates on the existing standard.

Changes were brought on its core. Thus, a new version was proposed under the name ACCLIP "Accessibility for Learner Information Package ".

The ACCLIP is an extension of the LIP specifications v1.0 IMS [21]. This new specification adds components which define accessibility preferences.

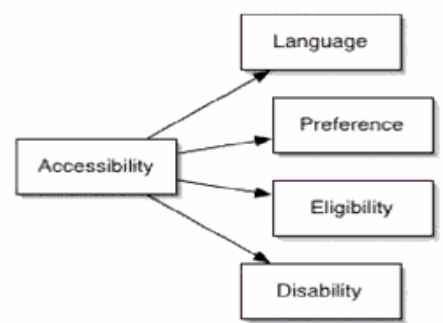

Figure 4. previous sub-elements of «Accessibility » in LIP.

These new elements added in the core are designed to be compatible with all the work carried out previously on the LIP with regard to the intimacy, the access and the integrity of information. They provide means to describe the preferences of a learner when he/she wants to access an elearning situation.

LIP "Learner Information Package" has been modified in the information model specification. At the beginning, the component "accessibility" was set up to make sure that the products and technologies are able to support handicapped people.

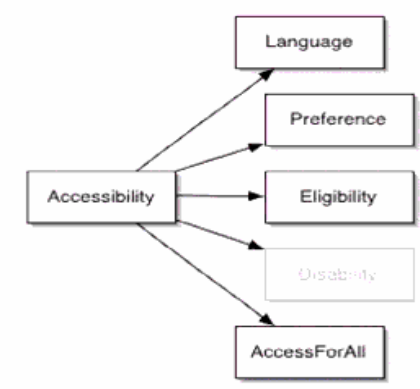

Figure 5. new sub-elements of « Accessibility » in LIP

The specification of this component was modified. A new element named "AccessForAll" was defined under the element "Accessibility". The "Disability" element was removed and another element named "Accommodation" was added under "Eligibility".

Figures 4 and 5 illustrate the various components modifications. This new presentation allowed the addition of the context under the new component "AccessForAll". 


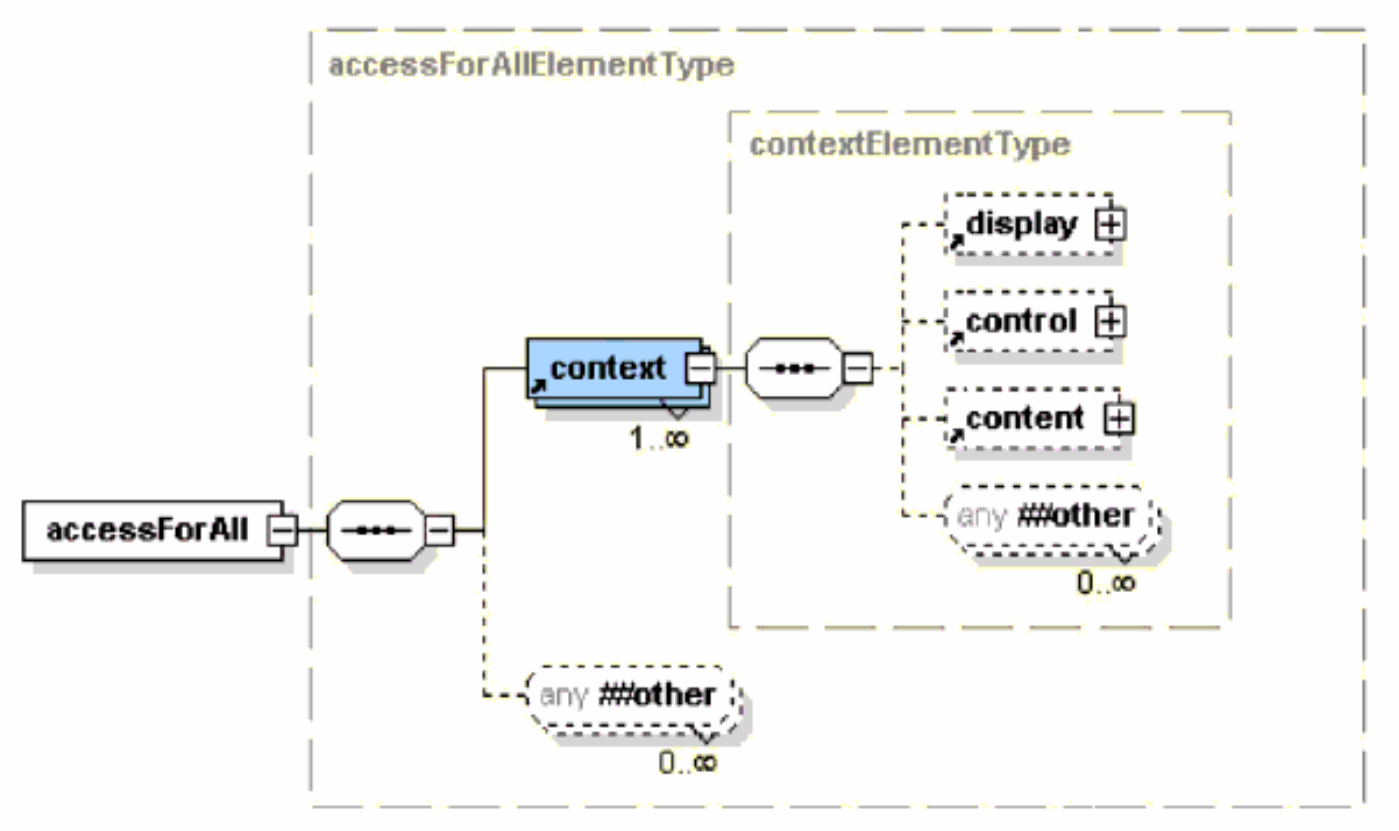

Figure 6. composition of the access for all elements

\section{B. ACCLIP definition of context:}

The new specification brought on the structure of the LIP on the level of the "Accessibility" component has led to the addition of a new element "AccessForAll" under which the context is defined. The figure 6 shows the composition of this element. The sub-elements of the context are of three Types:

\section{1) Display:}

It specifies the preference of display technology i.e how the user interface and the contents should be presented. This component has a paramount role in the display technique of the user interface. It describes in a detailed way the various parts which make an interface.

This element also defined the manner of display of the text, its color, and the sights contents. It includes also components which make it possible to define visual alert, the methods used during the sonorities integration.

2) Control:

It specifies the technologies which envisage alternative manners to command a device. This component will make it possible, for example, to control all the short cuts used by the keyboard, and the improvements in the keyboard. It defines components related to the mouse such as the speed of pointing, and sound alerts.

\section{3) Content:}

It specifies the preferences of the contents, indicating all desired transformations: determining the language used to describe the various components of the interface, and the way in which the additive contents will be presented.

\section{Limits of LIP context}

The part of the context, defined in the standard, provides only the least possible amount of information about the environment. It does not include the parts of the learner entourage. It is limited to define some components related to display, keyboard, mouse and the sound. These components are not sufficient when we aim to adapt content to a mobile learner. Mobile learner implies constraints related to device such as small screens, limited autonomy, limited scale of colors, limited size of programs etc. Constraints are also related to environments: connectivity, noise, luminosity etc.

Since, we are interested in the content adaptation to learner in a mobile learning situation and we project to use LIP as a standard for the modeling learner attributes, we propose to enrich ACCLIP.

\section{The core of C-LIP}

We have demonstrated that the element context defined in LIP isn't sufficient to model mobile learner.

Figure 7 explains the element context added to the core of LIP. The extension is mainly represented by the context which is characterized by its nature, extension and origin and in order to manage Contextual elements, we must differentiate between them by giving them different features. Table 1 illustrates these features: nature, acquisition type, acquisition mode, relevance, evolution, adaptation and frequency of updating. The extended LIP is labelled C-LIP for context LIP. Elements of context depend on scenario and use of mobile device. Figure 7 shows the new core of LIP. The core takes into account the context with elements predefined in LIP. Elements in the added context are more detailed in order to give an idea about all features. Technically, theses features are coded as metadata in an XML file.

Once the core of C-LIP is defined, we thought of facilitating the task of the teacher by offering him/her a tool allowing data acquisition for C-LIP. The editor is based on the core of LIP and offers the traditional fields of the LIP and the new fields induced by mobility. 


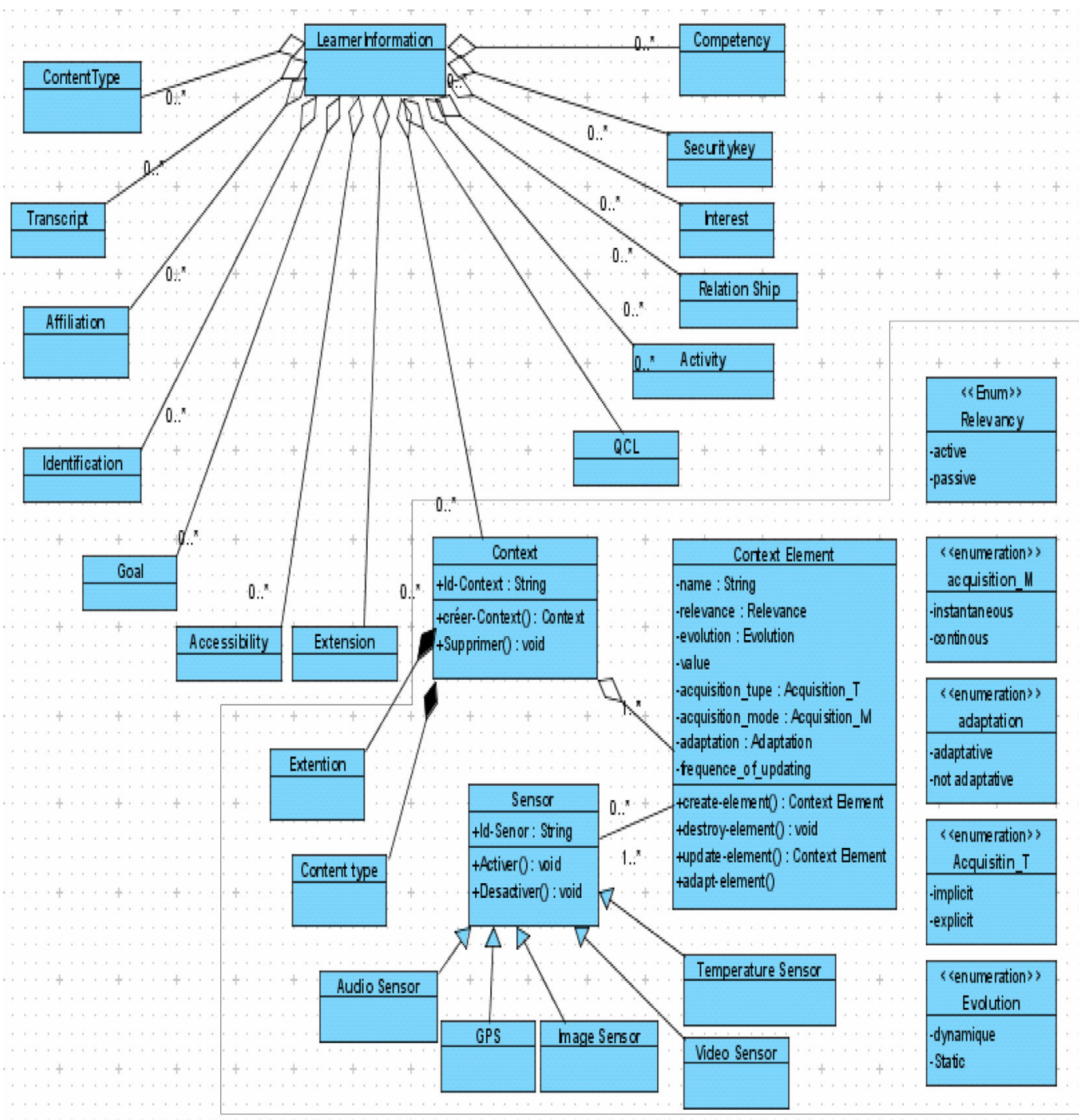

Figure 7. The added elements in the core of LIP

TABLE I.

CONTEXTUAL ELEMENT FEATURES

\begin{tabular}{|l|l|}
\hline \multicolumn{1}{|c|}{ Contextual element features } & \multicolumn{1}{c|}{ Possible values } \\
\hline Nature & $\begin{array}{l}\text { Natural: temperature } \\
\text { Artificial: the sound of the stereo channel }\end{array}$ \\
\hline Acquisition type & $\begin{array}{l}\text { Explicit acquisition: contextual element is directly acquired. } \\
\text { Automatic acquisition: contextual element is sensed automatically (e.g., by } \\
\text { sensors). } \\
\text { Manual acquisition: contextual elements are given by learner. } \\
\text { Implicit acquisition: contextual elements are inferred from others stored contextual } \\
\text { element. }\end{array}$ \\
\hline Acquisition mode & $\begin{array}{l}\text { Instantaneous: contextual element is acquired only once at the beginning of the } \\
\text { interaction (e.g., date) } \\
\text { Continuous: contextual element is acquired continuously during an M-learning } \\
\text { session (e.g., noise level). }\end{array}$ \\
\hline Relevance & $\begin{array}{l}\text { Active: contextual element relevant to the interaction between learner and the } \\
\text { system ( e.g., if learning type is a Visio-conference, noise level is an active element) } \\
\text { Passive: isn't relevant to a given interaction between learner and the system (e.g., if } \\
\text { the learner's task consists of reading a text, the name of learner is a passive } \\
\text { element). }\end{array}$ \\
\hline Evolution & $\begin{array}{l}\text { Dynamic: contextual element change during the interaction (e.g., noise level). } \\
\text { Static: contextual element does not change during interaction (e.g., season). }\end{array}$ \\
\hline Adaptation & $\begin{array}{l}\text { Adaptable. } \\
\text { Not adaptable. }\end{array}$ \\
\hline Frequency of updating & This feature ensures the newness of contextual elements. \\
\hline
\end{tabular}




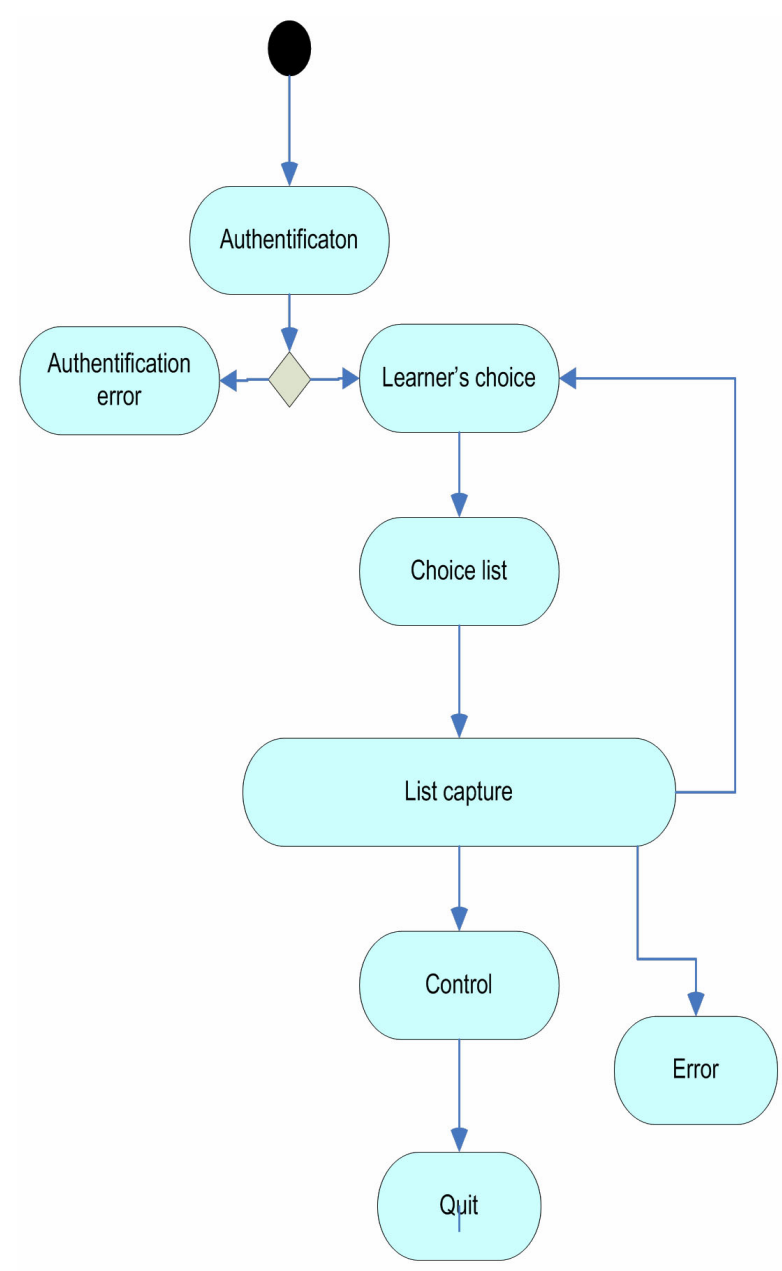

Figure 8. Workflow of activity diagram in C-LIP

\section{VIII.C-LIP EDITOR}

\section{A. Functional architecture}

We have designed and implemented C-LIP editor. This editor enables a semi-automatic incremental data acquisition of C-LIP fields.

Figure 8 explains the workflow function of C-LIP editor. After authentication the teacher selects student and completes the missing elements of C-LIP.

This incremental editor doesn't overload the teacher. All fields are optional and data are stored between sessions and can be restructured incremented or suppressed. The teacher makes his/her choice between different elements composing LIP and those elements appear as angles in the following interfaces (figure 10).

This editor gives the opportunity to the teacher to personalize his/her course using data saved in C-LIP. This personalization can either display the name or forename of the student only or include details about learning styles, profiles and/or mobile devices used in a particular context.

Each element of the interface implies a new interface with elements composing it.

\section{B. Technical details}

The data are stored in XML file (Figure 9). XML file enables the reuse and the interoperability of the information even after extension. For each group, teacher disposes of file regrouping all students of a group.

\section{Tests and evaluations}

The C-LIP tool was tested in classroom study involving students and teachers. Each student received a handheld Pocket PC that could be used in all classes, and taken home, and thus could access the Internet via the school's wireless network.

In order to better understand the use of C-LIP, two aspects are examined. First, from the students' point of view we evaluate whether the use of this software enhances the quality of content and second from the teachers' point of view.

Does the use of C-lip bother the teacher?

How can the teacher use results of C-lip to adapt courses?

The primary data analyzed for this experimentation was collected from students and teachers.

At the beginning, some teachers found the form filling and the use of the interface of C-LIP very timeconsuming. But they found this context modelling to adapt course material very useful.

Some students had difficulty understanding or using interface elements but they enjoyed finding personalized interface.

This small evaluation highlights several issues that should be considered for the next version such as the number of pertinent questions about the real role of student and teacher etc.

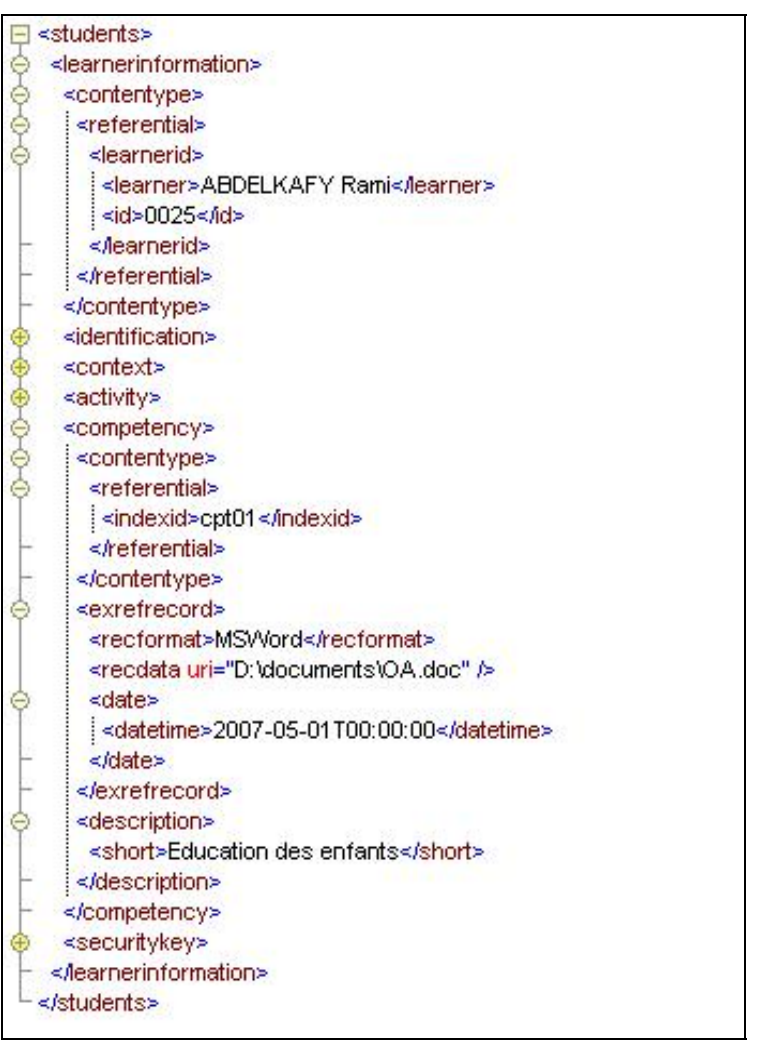

Figure 9. XML storage 


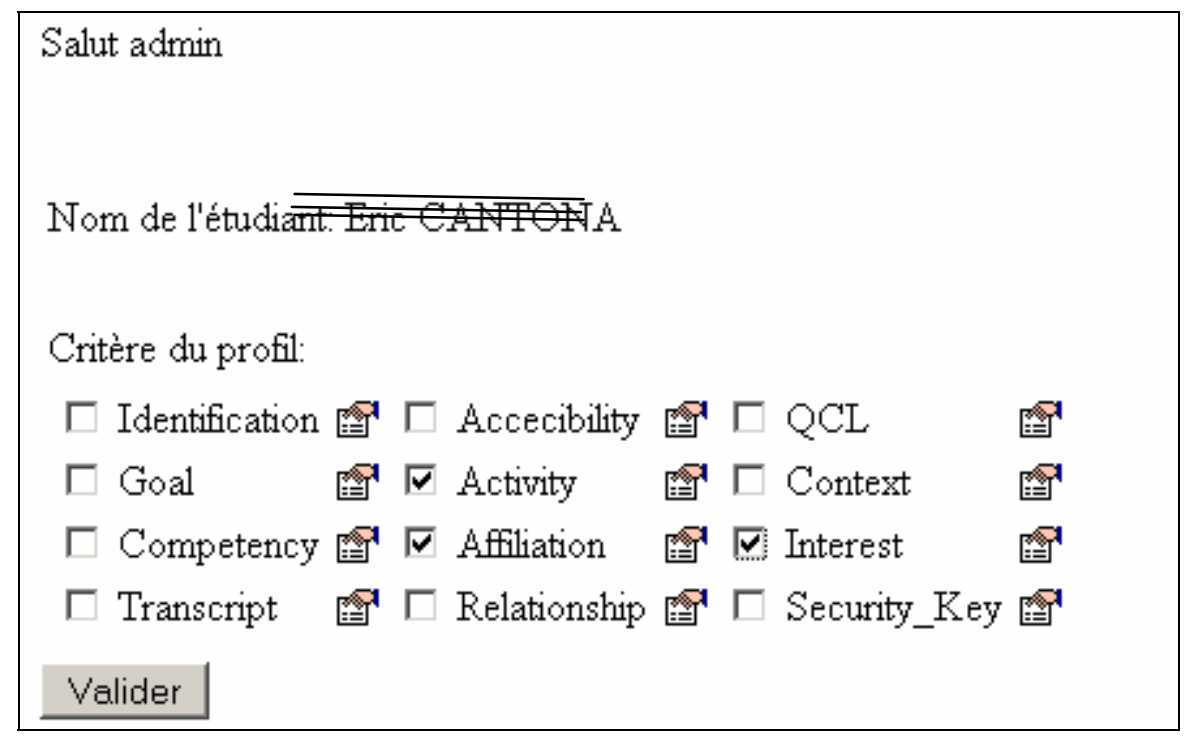

Figure 10. elements choice interface in LIP editor

\section{CONCLUSION AND FUTURE WORK}

The focus of this paper was adaptive mobile learning by the use of an extended LIP. The investigation of existing learner modeling standards revealed that the IMS LIP specification is not sufficient to model mobile learner.

Thus, we proposed an extension of the LIP core in order to introduce new contextual elements induced by mobility.

Adding context in the learner model enabled us to model new elements introduced by mobility. The editor C-LIP facilitates the task in the sense that the teacher is not obliged to handle directly an XML. The result of its modelling can be read by any LMS.

The inconvenience is that all the fields are captured by the teacher and are not automatically deduced from various work of learner. We are now working on analysing learning session traces to aid learner model.

We plan to integrate C-LIP environment in web service learning platform SOLEIL [18] using SCORM as learning resource standard.

We mention that, in the same project SOLEIL, we have proposed an adaptation of SCORM to support learner's learning styles and mobility [3].

We project to create a web service based on CLIP editor providing interoperable and distributed mobile learner contextual LIP.

\section{REFERENCES}

[1] Anind K. DEY, Understanding and Using Context, Personal and Ubiquitous Computing, Volume 5, Issue 1, February 2001, Pages: 4 - 7.

[2] P. Brusilovsky,. and C. Peylo, (2003) Adaptive and intelligent Web-based educational systems. In P. Brusilovsky and C. Peylo (eds.), International Journal of Artificial Intelligence in Education 13 (2-4), Special Issue on Adaptive and Intelligent Web-based Educational Systems, 159-172.

[3] R. Drira, M. Laroussi, A. Derycke., «SCORM dans l'apprentissage mobile». Atelier Apprentissage mobile EIAH'07, Lausanne Juin 2007.

[4] J. Ensing, Software architecture for the support of context aware applications, Preliminary study, February 2002.

[5] V. Jo, Jones Ubiquitous Learning Environment: an Adaptive Teching System using Ubiquitous Technology. In R Atkinson, Mcbeath, Joans-Dwyer (eds) Beyond the comfort zone:proceeding of the ASCILITE conference, Perth, Australia, 5-8 December 2004, pp 468-474.

[6] S. Iksal, Declarative specification and semantic composition for adaptive virtual documents. PHD thesis, December 2002.

[7] M. Kaenampornpan,., O’Neill, E., An Integrated Context Model: Bringing Activity to Context, in "Workshop on Advanced Context Modelling, Reasoning and Management", UbiComp 2004, Nottingham, UK, 2004.

[8] Kinshuk \& T Goh. (2003). Mobile Adaptation with Multiple Representation Approach as Educational Pedagogy. In Uhr W., Esswein W. \& Schoop E. (Eds.),

[9] ,Keil-Slawick, R. Hampel, T. Ebman, B. ReConceptualising Learning Environments: A framework for Pervasive eLearning. Proceedings of 3rd Int'l conf. on Pervasive Computing and Communication (PERCOM), IEEE press, 2005, 6 p.

[10] Kay, A., \& Goldberg, A. (1977, March Conlpurer; 10(3), 31-42. (Reprinted in A. Goldberg (Ed.). (1988). A history of tations (pp. 254-263). Reading,MA: Addison-Wesley.)

[11] M. Laroussi, Conception et réalisation d'un système hypermédia adaptatif didactique : Le système CAMELEON, PhD Thesis, Ecole National des Sciences Informatiques, Tunis, Mars 2001.

[12] M. Laroussi, A. Derycke, New e-learning services based on mobile and ubiquitous computing, CALIE’04, Grenoble France, february2004.

[13] Z. Maamar, S. Mostéfaoui, Q. Mahmoud, Context for Personalized Web Services, Proceedings of the 38th Hawaii International Conference on System Sciences 2005.

[14] J. Malek., M Laroussi., A Deryicke., "How to adapt context to mobile and collaborative learning", Multichannel Adaptive Context-sensitive systems Workshop (MAC'06), University of Glasgow, 15th May 2006.

[15] R. Rupnik, M. Krisper, M. Bajec, A new application model for mobile technologies, International Journal of Information Technology and Management (IJITM), Vol. 3, No. 2/3/4, 2004 
[16] .Salber, A.Dey and G. Abowd, Designing and Building Context-Aware Applications, 2001.

[17] K Sushil. Sharma and Fred L. Kitchens, Web Services Architecture for M-Learning, Electronic Journal on eLearning Volume 2 Issue 1,P 203-216, February 2004;

[18] I. Tirellil, M. Hajjouni, M. Laroussi; "Mobile and collaborative platform based on web services”. ML'05 Malte Juin 05.

[19] L. Uden,. 'Activity theory for designing mobile learning', Int. J. Mobile Learning and Organisation, Vol. 1, No. 1, pp.81-102. (doi:10.1504/IJMLO.2007.011190)

[20] Learning Tecnology standards committee: http://lsc.ieee.org

[21] IMS Consortium: http://www.imsproject.org.

[22] PAPI (2000). Public and Private Information; IEEE 2000, Draft Standard for Learning Technology - Public and Private Information (PAPI) for Learner, IEEE P1484.2/D6, 2000. http://tsc.ieee.org/

\section{AUTHORS}

M. Laroussi (e-mail: mona.laroussi@univlille1.fr) is currently Assistant Professor at the Department of Computer Science in National Institute of applied sciences and Technology (Tunisia) and an associated researcher in Noce Laboratory (Lille France) http://noce.univlille1.fr/cms/

A. Derycke. (e-mail: alain.derycke@univlille1.fr), is currently Professor in University of science and technology of Lille1. He is also the director of Noce Laboratory (Lille France) http://noce.univ-lille1.fr/cms/

Manuscript received 10 december 2008. Published as submitted by the authors. 